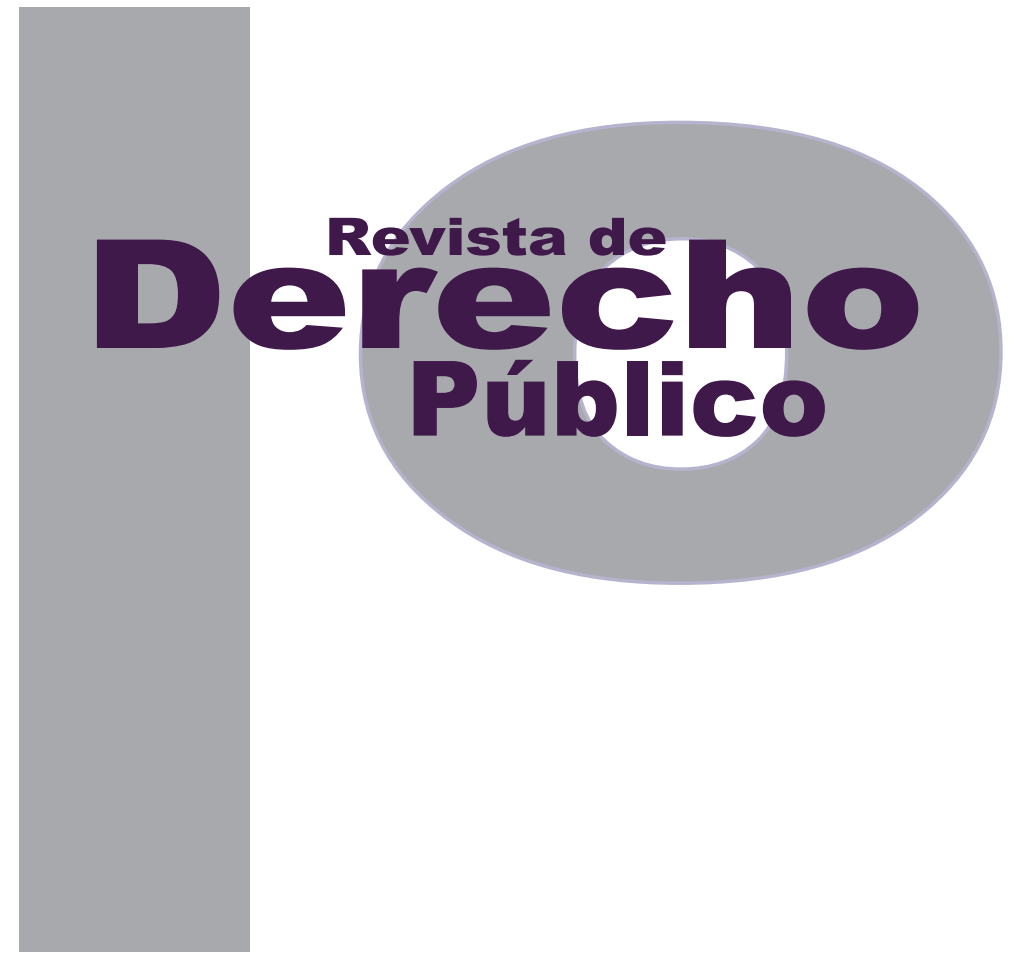

\title{
LA SOSTENIBILIDAD FISCAL: DESAFÍO AL ESTADO SOCIAL DE DERECHO EN COLOMBIA
}

\author{
Francisco R. BARBosa DELGADO
}

\author{
Artículo de reflexión
}

DOI: http://dx.doi.org/10.15425/redepub.33.2014.21

Universidad de los Andes

Facultad de Derecho

Revista de Derecho Público N. ${ }^{\circ} 33$

Julio - Diciembre de 2014. ISSN 1909-7778 


\section{La sostenibilidad fiscal: desafío al Estado social de derecho en Colombia}

\section{Resumen}

El presente artículo busca determinar en qué sentido el criterio de sostenibilidad fiscal plantea un desafío a la existencia del Estado social de derecho en Colombia.

Palabras clave: sostenibilidad fiscal, Estado de derecho, Colombia, democracia.

\section{Fiscal sustainability and rule of law in Colombia}

\section{Abstract}

This article seeks to determine in what sense the criterion of fiscal sustainability poses a challenge to the existence of the rule of law in Colombia.

Keywords: fiscal sustainability, rule of law, Colombia, democracy.

\section{A sustentabilidade fiscal: desafio ao Estado social de direito na Colômbia} Resumo

O presente artigo busca determinar em que sentido o critério de sustentabilidade fiscal apresenta um desafio à existência do Estado social de direito na Colômbia.

Palavras-chave: sustentabilidade fiscal, Estado de direito, Colômbia, democracia. 


\title{
La sostenibilidad fiscal: desafío al Estado social de derecho en Colombia*
}

\author{
Francisco R. Barbosa Delgado**
}

"Estabelecer teorias, pensando-as paciente e honestamente, só para depois agirmos contra elas- agirmos e justificar as novas ações com teorias que as condenam. Talhar um caminho na vida, e em seguida agir contrariamente a seguir por esse caminho. Trecho 23". Fernando Pessoa (2011, p. 56)

“El capitalismo moderno es absolutamente irreligioso, sin unión interna, sin gran espíritu público, a menudo, aunque no siempre, una mera agregación de aquellos que poseen y aquellos que persiguen poseer. Tal sistema ha de ser no solo moderadamente, sino inmensamente exitoso para sobrevivir". John Maynard Keynes

“Una de las pérdidas más tristes de la sociedad moderna es la del sentido de comunidad. Imaginamos que existió alguna vez un grado de cercanía y buena vecindad que ahora ha sido sustituido por un anonimato implacable, por una situación en que las personas buscamos el contacto con el otro principalmente con fines bien demarcados y egoístas".

Alain de Botton (2012, p. 23)

\section{SUMARIO}

Introducción - I. PRECISIONES CONCEPTUALES - A. Estado social de derecho - B. Democracia - C. Sostenibilidad Fiscal - II. SUSTITUCIÓN CONSTITUCIONAL: ALTERACIÓN SOBRE LA COSA JUZGADA, LA SEPARACIÓN DE PODERES Y EL CONTENIDO PRESTACIONAL DE LOS DERECHOS- A. Sobre la cosa juzgada - B. Separación de los poderes - C. La progresividad y el contenido prestacional de los derechos fundamentales - III. DE LA INCONVENIENCIA DE CONVERTIR UNA TESIS ECONÓMICA CUESTIONADA EN UNA REGLA CONSTITUCIONAL: AUSENCIA DE INSTITUCIONES INCLUSIVAS Y PACTO SOCIAL - IV. CONSIDERACIONES FINALES - Referencias.

* $\quad$ Cómo citar este artículo: Barbosa Delgado, F. R. (Diciembre, 2014). La sostenibilidad fiscal: desafío al Estado social de derecho en Colombia. Revista de Derecho Público, 33. Universidad de los Andes (Colombia).

** Doctor en Derecho Público de la Universidad de Nantes en Francia. Magíster en Derecho Público de la Universidad Externado de Colombia, y en Historia de la Pontificia Universidad Javeriana. Especialista en Regulación y Gestión de Nuevas Tecnologías de la Universidad Externado de Colombia. Abogado de la Universidad Sergio Arboleda. Docente e investigador del Departamento de Derecho Constitucional de la Universidad Externado de Colombia (categoría junior, Colciencias). Profesor invitado de la Universidad de Nantes en Francia. Miembro de la Academia Colombiana de Jurisprudencia y de la Academia Colombiana de Historia. Correo: francisco.barbosa@uexternado.edu.co. 


\section{Introducción}

Los objetivos de esta contribución académica son, en primer término, determinar en qué sentido el criterio de sostenibilidad fiscal plantea un desafío a la existencia del Estado social de derecho. Esa constatación tiene como corolario la mutación del Estado social de derecho a un simple Estado fiscal. En segundo término, se hace un análisis jurídico de cómo este principio en Colombia no hace parte solamente de una preocupación fiscal sino que, por el contrario, es parte de una alteración del modelo establecido en 1991, conforme a los dictados de clubes económicos como la Organización para la Cooperación y el Desarrollo Económicos (OCDE) y las imposiciones del Fondo Monetario Internacional (FMI).

Para efecto del desarrollo el artículo se dividirá en tres partes. En la primera se realizarán unas precisiones conceptuales para entender desde qué lugar este se escribe. La segunda demostrará la sustitución constitucional que obró a través del Acto Legislativo nº 3 de 2011, contrariando varias cláusulas de intangibilidad de la Constitución de 1991. En la tercera se explicará la inconveniencia de haber convertido una tesis económica cuestionada en una norma constitucional. Esta aplicación mostrará la imposibilidad de utilizar ese criterio cuando se carece de instituciones económicas y políticas inclusivas, lo que producirá en Colombia una mayor alteración del pacto social en términos de la desestimulación del uso de las acciones de protección constitucional, y una inseguridad jurídica frente a los procesos de responsabilidad extracontractual.

\section{PRECISIONES CONCEPTUALES}

\section{A. Estado social de derecho ${ }^{1}$}

Abordar la noción de Estado de derecho no es tarea fácil. Su complejidad radica en que ha sido tratado por la doctrina desde diferentes puntos de vista. Para efecto de aclarar el tipo de concepto sobre el cual se debe entender se explicará cada uno de ellos. Con lo anterior, se evidenciará su problematización a través de la lectura doctrinal multidisciplinar. En cuanto al Estado, son los juristas quienes lo han definido y explicado de forma amplia.

Antes de abordar su noción, es menester hacer un pequeño rastreo desde el punto de vista histórico al Estado de derecho. Para el profesor Villar Borda (2007), este concepto tiene origen alemán, fundado en los postulados del profesor Robert von Mohl (1799-1875), que lo ubica desde el centro del poder e incluye tareas como el cumplimiento de los derechos económicos y sociales (pp. 74-76). El profesor Heinz Mohnhaupt, citado por Villar Borda, establece que "ese Estado de derecho constituye el único medio que permite lograr una expansión de la personalidad individual y su promoción" (2007, pp. 74-76). Esta manifestación decimonónica alemana fue acogida por los profesores Francis Carré de Malberg y Leon Duguit. Sintetizando su artículo, Villar Borda enuncia varios elementos que se coligen de estas elaboraciones

Parte de este apartado fue tomado y actualizado de mi libro El margen nacional de apreciación y sus límites en la libertad de expresión, publicado por la Universidad Externado de Colombia en el 2012 (pp. 52-53). 
teóricas germano-francesas: (i) la existencia de una Constitución escrita; (ii) separación de los poderes; (iii) principio de legalidad; (iv) principio de garantía de los derechos fundamentales; (iv) seguridad jurídica y protección de la confianza; (v) principio de proporcionalidad (2007, 74-95). Estos elementos son percibidos en las diferentes manifestaciones teóricas que se expondrán.

Para hacerlo, debe observarse algunas visiones del Estado. Retendremos tres. Jean Gicquel y Jean Eric Gicquel, por ejemplo, consideran que el Estado "está compuesto por un grupo humano, fijado en un determinado territorio y sobre el cual una autoridad política exclusiva se ejerce" (2008, p. 54). Kelsen, por su parte, lo definió como "un orden jurídico relativamente centralizado, limitado en su dominio de validez espacial y temporal y sometido inmediatamente al derecho internacional y a la eficacia general" (1999, p. 362).

Así pues, el Estado de derecho debe contener los elementos materiales del territorio y soberanía, y debe concebir el carácter nacional desde el punto de vista subjetivo. Esta postura está conforme con lo establecido en el artículo 1 de la Constitución Política de 1991, que define a Colombia como Estado social de derecho.

Desde el punto de vista colombiano, el Estado social y democrático de derecho no es creación del constituyente de 1991, sino una herencia de nuestra institucionalidad jurídica, cuya existencia se soslaya por la manida concepción de escribir la historia de Colombia exclusivamente en clave de guerra. Durante el siglo XX, la idea de Estado social fue establecida en la reforma constitucional de 1936, que para esa época era la regla general en países como Francia a través del gobierno del Front Populaire y del New Deal en los Estados Unidos. La estructura del Estado social de derecho se definió a través de las modificaciones al Código civil que incluyeron el desprendimiento del derecho civil al derecho social, a través de nociones como el abuso del derecho, enriquecimiento sin causa y la lesión enorme. Estas ideas vinieron acompañadas de un cambio en la manera de entender el nuevo Estado, que se materializó a través de algunas disposiciones del Acto Legislativo $n^{\circ} .1$ del 5 de agosto de 1936, que determinaron que la propiedad era una función social que implicaba obligaciones (art. 10), que el Estado podía intervenir por medio de las leyes la explotación de industrias o empresas públicas o privadas, con el fin de racionalizar la producción, distribución y consumo de las riquezas (art. 11), que la asistencia pública era función del Estado indicando que debe prestarse a quienes carecen de medios de subsistencia o estén físicamente incapacitadas para trabajar (art. 16), que el trabajo era una obligación social que gozaba de protección especial (art. 17) y que se garantizaba el derecho a la huelga (art. 20) (Restrepo Piedrahita, 2003, p. 481).

En esencia, se reemplazaba la lógica individualista propia del siglo XIX por otra en la cual lo social, lo colectivo, lo público adquiría relevancia. Era una Colombia en la que los intereses de clase permitían atisbar el surgimiento del derecho laboral a través de la gran reforma constitucional de 1945. Una Colombia en la 
que como indica el sociólogo Gonzalo Cataño se "sustituyó la teoría de la exégesis y el estilo de los glosadores del siglo XIX apegados a la teoría de la norma, por una interpretación más libre del derecho" (2013, p. 158). El discurso de los derechos fundamentales sustituía la tesis de los derechos individuales propia de las constituciones decimonónicas.

Esta es la idea que recoge la Constitución de 1991 que, reitero, no creó el Estado social de derecho, sino que lo heredó. En ese sentido, en esta contribución académica cuando se indique Estado social y democrático de derecho no se debe tener en cuenta solamente el artículo 1 de la Constitución Política y la jurisprudencia de la Corte Constitucional, sino el concepto de Estado social y democrático de derecho explicado con anterioridad.

\section{B. Democracia ${ }^{2}$}

Para abordar la democracia es necesario hacerlo a través de tres posturas. Una de carácter formalista o instrumental, otra sistémica y, la tercera, desde el punto de vista sociológico. En cuanto al primer tipo debe indicarse que su preocupación radica en los aspectos jurídicos y formales de la democracia. Su objetivo no es otro que sobrevalorar los procedimientos formales de elección, sin tomar en cuenta los aspectos metademocráticos que se sobreponen al simple mecanismo ciudadano de depositar un sufragio

2 Este apartado fue tomado y actualizado de mi artículo: La democracia: un concepto base dentro de los sistemas de protección de derechos humanos, publicado en Revista Derecho del Estado, (27), juliodiciembre de 2011. en las urnas durante un periodo electoral. Es lo que el Programa de Naciones Unidas para el Desarrollo ha denominado democracia electoral (2004, p. 54). En ese camino se encuentra el estudio de Pactet y Mélin quienes limitan la democracia a una regla formal cuyos componentes son el pluralismo y el principio de las mayorías (2008, pp. 84-85). Esta forma de democracia es protegida a través del artículo 3 del protocolo 1 del Convenio para la Protección de los Derechos Humanos y de las Libertades Individuales (CEDH) y el artículo 23 de la Convención Americana sobre Derechos Humanos (CADH).

La segunda, por su parte, plantea un concienzudo análisis de la democracia desde el punto de vista material, es decir, no solo sus mecanismos de funcionamiento, sino su concretización práctica. Esta forma de entender la democracia ha sido respaldada por los profesores Jurgen Habermas, Bjarne Melvevik y Pierre Rosanvallon, quienes coinciden en sus reflexiones ubicándose en una postura sistémica de esta. Para el primero, el proceso democrático implica que los ciudadanos participen de forma activa en la elaboración de las normas sociales, constituyéndose en autores racionales de estas, es decir, cuando el procedimiento de creación de las normas reproduce el procedimiento argumentativo y consensual de la razón comunicativa (García Amado, 1997, p. 19). Melvevik considera la democracia como el lugar en donde nos afirmamos recíprocamente como autores de nuestros derechos y, sobre todo, donde realizamos democráticamente el proyecto de un "nosotros jurídico" (2006, p. 121). Rosanvallon estima que la democracia no debe limitarse a la verificación 
de un procedimiento formal eleccionario; por el contrario, opina que para que la democracia sea integral debe existir una democracia de la apropiación en la cual se distinguen dos aspectos: (i) una política ciudadana de la desconfianza que contrasta con la confianza propia del ejercicio electoral y permite la construcción de una sociedad civil que controle el ejercicio del poder y (ii) el funcionamiento de los organismos de democracia indirecta, tales como las Cortes Constitucionales, autoridades independientes de regulación, entre otras (2008, pp. 347-350).

Desde la teoría del derecho, Kelsen indicó que la democracia no era posible concebirla sin la existencia de la libertad y la igualdad. Para el jurista alemán "las teorías de extrema derecha o marxistas no pueden ser consideradas como democráticas" (1988, p. 16 y ss.). Esta postura de Kelsen explica muy bien cómo dentro del campo de los derechos humanos es imprescindible la democracia, y cómo factores intrínsecos de esta como la libertad o la igualdad coinciden con la arquitectura teórica de los derechos fundamentales. Por su parte, Loewenstein acuñó la expresión democracia constitucional indicando que esta "depende de la existencia o carencia de las instituciones efectivas por medio de las cuales el ejercicio del poder político esté distribuido entre los detentadores del poder, y por medio de las cuales los detentadores del poder estén sometidos al control de los destinatarios del poder" (1964, p. 149).

La tercera se ha trabajado desde el derecho internacional de los derechos humanos, que permite su variante sociológica. Veronique Fa-
bre-Alibert (1998, pp. 465-496) indica que la sociedad democrática ha sido entendida como un conjunto de tres elementos esenciales: el pluralismo, ${ }^{3}$ la tolerancia y el espíritu abierto. El primero es definido por la autora como aquel que: "supone que sean tomadas en cuenta las diferentes tendencias y corrientes de ideas en una sociedad políticamente dada". Para la profesora Cassenove, "la idea de pluralismo gobierna la estructuración del orden jurídico europeo de los derechos humanos. El orden jurídico europeo es en efecto un orden plural que permite la singularidad de órdenes estatales" (1994, p. 338).

El segundo elemento Fabre-Alibert lo define como "la línea de conducta que consiste en dejar vivir a otra persona conforme a los principios a los cuales uno no adhiere" (1998, p. 494). Esta definición de tolerancia se articula con la pluralidad, permitiendo que dentro del universalismo de los derechos consagrados en las convenciones regionales sobre derechos humanos se permita la posibilidad de explicar las voces disonantes que existen. La tercera condición es el espíritu abierto, es decir, la actitud de aceptación que debe existir en una sociedad democrática. Para la Corte EDH, el espíritu abierto es otro elemento principal dentro de la democracia, categoría que reafirma las posturas liberales que deben existir en su interior, sin caer en ningún tipo de fundamentalismo ideológico o religioso.

\footnotetext{
3 El Tribunal Europeo de Derechos Humanos (TEDH) consideró "que no existe democracia sin pluralismo". Caso Partido Comunista Unificado de Turquía c. Turquía, 30 de enero 1998, p. 43.
} 
Las decisiones de las Cortes regionales de derechos humanos, al mismo tiempo, no solo observan las medidas y las confrontan con la existencia de una sociedad democrática, sino que sus decisiones judiciales son en sí mismas democráticas, teniendo en cuenta que la acción judicial internacional deviene de la voluntad estatal de firmar y ratificar los convenios respectivos, reconociendo voluntariamente las competencias de dichas Cortes. Esta acción descarta el Ilamado "gobierno de jueces" ${ }^{4}$ dentro del ámbito interna

En síntesis, las Cortes regionales de derechos humanos y la doctrina especializada han entendido la democracia como una elaboración sistémica que comporta aspectos formales y materiales. Esto quiere decir que "las elecciones libres no son por ellas mismas insuficientes $\mathrm{y}$, por ende, no garantizan per se los derechos humanos" (Van Voben, 1990, p. 127), sino que es necesario que exista una democracia material en la cual el pluralismo y la tolerancia sean la regla y no la excepción. En sus preámbulos,

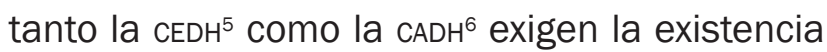
de la democracia como elemento esencial para pertenecer a los sistemas de protección de los

4 Sobre este punto, véase Troper, M. (2004). Le pouvoir judiciare et la démocratie. En Libertés, justice, tolérance. Mélanges en hommage au doyen Gérard Cohen-Jonathan, vol. II. Bruxelles: Bruylant, pp. 15711586.

5 En el preámbulo del CEDH se lee: "Reafirmando su profunda adhesión a estas libertades fundamentales que constituyen las bases mismas de la justicia y de la paz en el mundo, y cuyo mantenimiento reposa esencialmente, de una parte en un régimen político verdaderamente democrático, y de otra, en una concepción y un respeto comunes de los derechos humanos de los cuales dependen".

6 En el preámbulo de la CADH se lee: "Consolidar en este Continente, dentro del cuadro de las instituciones democráticas, un régimen de libertad personal y de justicia social, fundado en el respeto de los derechos esenciales del hombre". derechos humanos. En ella, los "sistemas regionales encuentran el fundamento de su existencia en el marco de la organización democrática" (Gross Espiell, 1998, p. 441). La democracia es entendida, entonces, como el espacio en el cual se respeta el pluralismo, la tolerancia de las personas, se acatan los derechos humanos, se desarrollan las relaciones de confianza con sus instituciones y se entiende la participación y “la libre discusión” (Wachmann, 1998, p. 166) como factor esencial de legitimidad.

\section{Sostenibilidad fiscal}

Para efecto de esta contribución académica, se tomará en cuenta lo indicado por la Corte Constitucional en cuanto a este criterio:

El criterio de SF está dirigido a disciplinar las finanzas públicas, de manera tal que la proyección hacia su desarrollo futuro reduzca el déficit fiscal, a través de la limitación de la diferencia entre los ingresos nacionales y los gastos públicos. Esto a partir de la evaluación de esa diferencia entre los distintos presupuestos sucesivos y de los factores endógenos y exógenos que la aumentan o reducen (C-288 del 18 de abril de 2012, párr. 30).

Conforme a lo anterior, este criterio pretende limitar la diferencia entre los ingresos y los gastos de un Estado. Su aplicación paulatinamente llevará a reducir los déficits fiscales hasta llegar a un equilibro en el manejo de la economía. 


\section{SUSTITUCIÓN CONSTITUCIONAL: ALTERACIÓN SOBRE LA COSA JUZGADA, LA SEPARACIÓN DE PODERES Y EL CONTENIDO PRESTACIONAL DE LOS DERECHOS ${ }^{7}$}

A pesar de que la Corte Constitucional se pronunció a través de la sentencia C-288 de 2012 avalando el Acto Legislativo $n^{\circ} .3$ de 2011, y decidiendo la implementación de ese criterio de sostenibilidad fiscal en el ordenamiento jurídico colombiano por cuanto no desconocía el principio de separación de los poderes públicos, la concretización de los derechos fundamentales ni la cláusula del Estado social y democrática de derecho, en la presente sección se demostrará cómo sí operó una sustitución desde el punto de vista de tres conceptos constitucionales.

La primera es la realización de los derechos a través del cumplimiento del principio de lege ferenda. La segunda se presenta con la idea de que todos los derechos son realizables y, por último, la sustitución constitucional que obró con la sentencia en torno a la alteración al principio de la separación de los poderes.

\section{A. Sobre la cosa juzgada}

El principio de cosa juzgada se desconoce en el Acto Legislativo n'. 3 de 2011, por cuanto se permite que las altas Cortes, una vez ya proferido el fallo, deban resolver un incidente de

7 Parte de este apartado fue tomado y actualizado de mi libro El margen nacional de apreciación y sus límites en la libertad de expresión, publicado en el 2012 por la Universidad Externado de Colombia. impacto fiscal presentado por el procurador general de la Nación o los ministros del Gobierno, abriendo la posibilidad de modular, modificar o diferir los efectos de la decisión. Veamos cómo quedó redactado el párrafo del artículo 334 de la Constitución Política:

El Procurador General de la Nación o uno de los Ministros del Gobierno, una vez proferida la sentencia por cualquiera de las máximas corporaciones judiciales, podrán solicitar la apertura de un Incidente de Impacto Fiscal, cuyo trámite será obligatorio. Se oirán las explicaciones de los proponentes sobre las consecuencias de la sentencia en las finanzas públicas, así como el plan concreto para su cumplimiento y se decidirá si procede modular, modificar o diferir los efectos de la misma, con el objeto de evitar alteraciones serias de la sostenibilidad fiscal. En ningún caso se afectará el núcleo esencial de los derechos fundamentales.

Esta situación no ofreció problema alguno a la Corte Constitucional al considerar que debía distinguirse entre la sentencia que ampara el derecho específico de una de las partes en la controversia y lo que el tribunal constitucional denomina "órdenes de protección", con las cuales el funcionario judicial adopta la forma como debe realizarse el derecho que se ha reconocido en la sentencia judicial. Esta postura de la Corte Constitucional se funda en un precedente: la sentencia T-086 de 2003. Para el máximo juez constitucional, la sentencia que ampara el derecho

está cobijada por los efectos estrictos de la cosa juzgada constitucional, lo que significa la imposibilidad de reversar la decisión de ampa- 
ro, no sucede lo mismo con las órdenes de protección. En este caso incluso resulta admisible que el juez, de manera excepcional, modifique el sentido de las órdenes originalmente proferidas, cuando concurran razones de primer orden, que así lo exijan en aras de proteger los derechos fundamentales concernidos. A su vez, esa distinción se explica en que muchos de los fallos de protección de derechos constitucionales no son simples, de ejecución inmediata y de una sola actuación, sino que pueden involucrar órdenes complejas, las cuales pueden extenderse por un periodo de tiempo, requerir varias actuaciones administrativas para su cumplimiento o estar precedidas de importantes operaciones presupuestales (sentencia C-288 de 2012, párr. 74.3).

Esta forzada postura de la Corte Constitucional, que le sirvió para avalar el acto legislativo en comento, pone en aprietos el principio de cosa juzgada en la medida en que no puede fraccionarse la decisión judicial. El pronunciamiento del juez es integral, esto es, debe existir un reconocimiento de un derecho y, al mismo tiempo, el juez lo debe garantizar con el propósito de hacerlo efectivo. De nada sirve la existencia de pronunciamientos judiciales si los efectos de la decisión quedan al amparo de nuevas interpretaciones políticas o judiciales, solicitadas por funcionarios que no pertenecen a la rama judicial. Más aún, en el caso del cambio constitucional, se permite presentar modificaciones a los efectos de las decisiones judiciales, poniendo del mismo modo en duda la existencia de la seguridad jurídica por la ruptura de la intangibilidad del fallo judicial.
Esta postura de la Corte dificulta no solo las acciones constitucionales, sino la misma premisa jurídica sobre la que se funda la responsabilidad en el derecho, según la cual "quien causa un daño, debe repararlo". Si se pone en juego la reparación, al arbitrio de "espacios de interlocución", el derecho como eje fundamental de solución de controversias podría llegar a la inanidad.

En una decisión anterior, la Corte Constitucional profirió la sentencia de tutela 016 de 2007 para efecto de sustentar su tesis, indicando:

una cosa es la fundamentalidad de los derechos y otra -muy distinta- la aptitud de hacerse efectivos tales derechos en la práctica o las vías que se utilicen para ese fin. En un escenario como el colombiano caracterizado por la escasez de recursos, en virtud de la aplicación de los principios de equidad, de solidaridad, de subsidiariedad y de eficiencia, le corresponde al Estado y a los particulares que obran en su nombre, diseñar estrategias con el propósito de conferirle primacía a la garantía de efectividad de los derechos de las personas más necesitadas por cuanto ellas y ellos carecen, por lo general, de los medios indispensables para hacer viable la realización de sus propios proyectos de vida en condiciones de dignidad. (Cursivas añadidas).

En esa decisión, la Corte planteaba que es el Estado el que crea mecanismos para garantizar la efectividad de los derechos, no para desconocerlos a través de la modulación, modificación o diferimiento de los efectos de los fallos. Recordemos que, por casos similares en el fracciona- 
miento de la sentencia y los efectos jurídicos, la $\mathrm{CIDH}$ ha condenado a Estados como Argentina, que en caso de violación de derechos humanos repara a las víctimas con bonos del tesoro. En el caso Furlan y familiares contra Argentina (CIDH, sentencia de 31 de agosto de 2012, párr. 43) el gobierno de dicho país interpuso una excepción preliminar por haber planteado una reserva al artículo 21 de la Convención Americana en virtud de la cual el tribunal internacional, decía el Estado, no era competente para discutir asuntos de la política económica interna. La CIDH desestimó la reserva, por cuanto los alegatos de los peticionarios buscaban discutir vulneraciones a dicho derecho derivadas del proceso judicial y la ejecución de este, y no plantear discusiones generales sobre una política económica del gobierno.

En el proceso, la CIDH condenó al Estado argentino por someter al señor Furlan a discusiones internas sobre los efectos económicos del fallo. Vale la pena indicar lo señalado por el máximo tribunal interamericano:

El proceso debe tender a la materialización de la protección del derecho reconocido en el pronunciamiento judicial mediante la aplicación idónea de dicho pronunciamiento. Por tanto, la efectividad de las sentencias depende de su ejecución. Esto último, debido a que una sentencia con carácter de cosa juzgada otorga certeza sobre el derecho o controversia discutida en el caso concreto y, por ende, tiene como uno de sus efectos la obligatoriedad o necesidad de cumplimiento. Lo contrario supone la negación misma del derecho involucrado.

\section{$(\ldots)$}

Al respecto, la Corte reitera que la ejecución de las sentencias debe ser regida por aquellos estándares específicos que permitan hacer efectivos los principios, inter alia, de tutela judicial, debido proceso, seguridad jurídica, independencia judicial, y estado de derecho. La Corte concuerda con el Tribunal Europeo de Derechos Humanos al considerar que para lograr plenamente la efectividad de la sentencia la ejecución debe ser completa, perfecta, integral y sin demora ( $\mathrm{CIDH}$, sentencia de 31 de agosto de 2012, párrs. 209 y 210).

Con este precedente, se abriría la posibilidad de que el sistema interamericano de derechos humanos pueda condenar al Estado colombiano por violaciones al artículo 21 -propiedad-al no garantizar los derechos reconocidos en sede judicial y, por ende, al no ser definitivo el cierre de los procesos judiciales por la intromisión en la discusión de los efectos económicos. Este tipo de procesos buscan determinar una responsabilidad internacional del Estado, es decir, aquella que se produce por acción u omisión de cualquier rama del poder público.

\section{B. Separación de poderes}

En la misma decisión, la Corte Constitucional consideró que no se desconoció el principio de separación de poderes públicos, toda vez que existe en el acto legislativo un espacio de interlocución entre las ramas ejecutiva y judicial, sin que se cuestione la intangibilidad de la rama judicial. 
Sobre este punto, indicó la Corte:

El incidente de impacto fiscal es (...) un espacio de interlocución entre los mencionados funcionarios y las altas cortes, donde se les confiere a aquellos la potestad de presentar explicaciones y argumentos a estas, relativos a la afectación de la sf por los efectos de una sentencia judicial. Esto implica que la Constitución impone una carga argumentativa particular a dichos servidores estatales, la cual no puede en modo alguno trasladarse a las altas cortes, sin contrariar con ello la regulación constitucional objeto de estudio (sentencia C-288 del 18 de abril de 2012, párr. 11).

La separación de los poderes públicos es el resultado histórico de una construcción teórica moderna del Estado que fundamenta la manera como se construyeron las repúblicas, luego de las revoluciones liberales. Colombia no ha sido ajena a esta tridivisión de poderes, que se ha manifestado en gran parte de la historia constitucional establecida a partir de 1821. La separación de poderes no se ha entendido en nuestro Estado como una formulación rígida y cerrada sino como una suerte de "colaboración armónica" entre los poderes instituidos. La misma Corte Constitucional en la sentencia C-141 de 2010 indicó que:

el balance de poderes es un resultado que se realiza y reafirma continuamente, mediante el control político, la intervención de unos órganos en las tareas correspondientes a otros y las relaciones de colaboración entre las distintas ramas del poder público en el ejercicio de sus competencias. En otras palabras, cada órgano tiene la posibilidad de condicionar y con- trolar a los otros en el ejercicio de sus respectivas funciones. (...), la Constitución de 1991, adopta un sistema flexible de distribución de las distintas funciones del poder público, que se conjuga con un principio de colaboración armónica de los diferentes órganos del Estado y distintos mecanismos de freno y contrapeso entre los poderes.

En Colombia se ha impuesto una tesis en torno a la colaboración armónica de los poderes públicos, derivada del artículo 116 de la Carta Política. La Corte Constitucional indica en la sentencia C-288 de 2012 que:

la separación de poderes en la Carta Política cumple dos tipos de funciones diferenciadas. La primera, relativa a garantizar las libertades y derechos de los ciudadanos, a través de la protección frente a la conformación de poderes públicos omnímodos. La segunda, dirigida a racionalizar la actividad del Estado y el ejercicio de ese poder político, mediante la instauración de órganos especializados, autónomos, independientes y con competencias definidas por la Constitución y la Ley (párr. 11).

En el caso concreto, pensar que el fundamento del espacio de interlocución son los efectos de una sentencia judicial, y que quien produce el espacio son los ministros y el procurador general de la Nación, plantea serias dudas sobre el equilibrio de la rama judicial en el marco de la separación de los poderes. No es posible imaginar que una vez se profiera la decisión judicial, otra rama del poder público pueda proponer un incidente de impacto fiscal en torno a los efectos del fallo. Esa sola acción de órganos ajenos a la rama judicial frente a la intangibilidad del 
fallo genera la violación de la cláusula de separación de los poderes. El hecho que sean las altas Cortes quienes decidan sobre ese incidente no sanea la acción previa de cuestionar lo incuestionable.

\section{La progresividad ${ }^{8}$ y el contenido prestacional de los derechos fundamentales}

La aplicación inmediata de los derechos civiles y políticos, y la aplicación progresiva de los derechos económicos, sociales y culturales tienen una importancia capital en las distintas clasificaciones que se han hecho a nivel nacional e internacional. La discusión entre ambos tipos de derechos se formula en materia tanto de su contenido esencial como de su instrumentalización dentro de los tratados internacionales de derechos humanos.

En cuanto a su contenido esencial, unos y otros tienen su razón de existir por cuanto poseen unos elementos ontológicos propios que impiden su confusión. Los derechos intangibles son lo que la doctrina del derecho internacional de los derechos humanos denomina "derechos civiles y políticos", que fueron construidos a través del Estado liberal de finales del siglo XVIII y durante todo el siglo XIX, en los cuales el Estado debía ser un actor pasivo en el ámbito de las relaciones establecidas entre los asociados.

8 Parte de este apartado fue tomado y actualizado de mi libro El margen nacional de apreciación y sus límites en la libertad de expresión, publicado por la Universidad Externado de Colombia en el 2012.
Los derechos económicos, sociales y culturales se construyeron justamente por la crisis del Estado liberal y la recuperación de la función del Estado en la comunidad. En síntesis, el Estado le puso límites al principio del laissez faire, laissez passer, que traducido en términos jurídicos se denomina "limitación de la autonomía de la voluntad".

Esta forma de entender los derechos se acompañó de una explicación jurídica ${ }^{9}$ en la cual se señaló que las dos categorías de derechos responden a una serie de obligaciones. Los derechos civiles y políticos atienden unas obligaciones negativas o de abstención del Estado en cuanto sea este el encargado de respetar el ejercicio de los derechos. Los derechos económicos, sociales y culturales, que como su denominación lo indica están condicionados en su cumplimiento a ciertas obligaciones, tienen una aplicación mucho más restringida en tanto que depende de obligaciones positivas, es decir, de que el Estado ponga en práctica una multiplicidad de acciones para hacerlos efectivos. ${ }^{10}$ Es lo que la doctrina especializada ha denominado "obligaciones positivas".

Para Abramovich y Courtis (2004) esta distinción radical de los derechos a partir de esque-

9 Sobre este punto puede destacarse el artículo de Antonio Javier Trujillo e Isabel Trujillo (2003), La polémique relative á la juridicité des droits sociaux. En L. Harmattan, Fondations et naissances des Droits de l'homme, pp. 429-438.

10

Se destaca la contribución de Valerie Liechti (2010, pp. 281-298) sobre la efectividad y la multidimensionalidad del derecho a la educación, en Mesurer l'effectivité del droit à l'education. En Le droit à l'education quelle universalité? Paris: Éditions des archives contemporaines. 
mas de obligaciones positivas y negativas es artificial por cuanto

la estructura de los derechos civiles y políticos puede ser caracterizada como un complejo de obligaciones negativas y positivas de parte del Estado: obligación de abstenerse de actuar en ciertos ámbitos y de realizar una serie de funciones, a efectos de garantizar el goce de la autoría individual e impedir su afectación por otros particulares. (...) Desde esta perspectiva las diferencias entre los derechos civiles y políticos y los derechos económicos, sociales y culturales son diferencias de grado, más que diferencias sustanciales (p. 25).

Esta posición doctrinal tiene sentido en la medida que justifica que tanto los derechos civiles y políticos como los derechos económicos, sociales y culturales contienen dentro de sus cuerpos normativos obligaciones negativas y obligaciones positivas; por ejemplo, garantizar la libertad de pensamiento y expresión implica, como su nombre lo indica, una obligación de abstención, pero al mismo tiempo plantea unas obligaciones positivas del Estado de adecuar todo el entramado normativo para que la libertad se pueda ejercer en el marco de unas condiciones efectivas y adecuadas. Esta manera de entender las obligaciones positivas supera el argumento de que su puesta en marcha implica el aprovisionamiento de fondos para su cumplimiento. Las obligaciones positivas, al decir de Abramovich y Courtis pueden entenderse a través de "la existencia de algún tipo de regulación, la existencia de regulación que limite o restrinja las facultades de personas privadas" (2004, p. 35), entre otras. Como se observa, distinguir los derechos por medio de sus obligaciones resulta antinómico por la conjunción de estas dentro de cada uno de los derechos.

Siendo esto así, el corolario sería que la desaparición de la distinción entre las obligaciones negativas y positivas en cuanto a los derechos intangibles y los derechos plantearía una disminución en el margen de apreciación del Estado en cuanto a su aplicación y, por ende, en su capacidad de garantizar en menor grado los derechos económicos, sociales o culturales o los mismos derechos políticos.

La Corte Constitucional, por su lado, ha acogido esa doctrina indicando que todos los derechos tienen un contenido prestacional. Esta postura es producto de los límites al margen de apreciación nacional derivados de las decisiones de la $\mathrm{CIDH}$, que se incorporan a nuestro ordenamiento a través del bloque de constitucionalidad emanado del artículo 93 de la Carta Política de 1991.

Por ser de gran importancia, vale la pena citar a la Corte Constitucional en la sentencia C-288 de 2012 que validó el acto legislativo contentivo del criterio de sostenibilidad fiscal sobre el aspecto que venimos tratando:

La actual jurisprudencia constitucional también ha señalado que el principio de progresividad no es solo aplicable a la categoría de los derechos sociales, sino que refiere a la faceta prestacional que tienen todos los derechos constitucionales, bien sean catalogados nominalmente como fundamentales, sociales o colectivos. Del mismo modo, estas distintas categorías de derechos adquieren carácter 
iusfundamental a partir de diversos criterios, relacionados con las particularidades del caso concreto, o su concreción legislativa como un derecho subjetivo. En ese sentido, es errónea la categoría de derechos prestacionales, en oposición a los derechos fundamentales, puesto que todo derecho constitucional tiene facetas de prestación, enmarcadas en la vigencia del principio de progresividad. Esto en razón del carácter indivisible e interdependiente de dichos derechos. Sobre el particular la Sala ha señalado que "todos los derechos fundamentales, tanto los derechos civiles y políticos como los derechos económicos, sociales y culturales, implican obligaciones de carácter negativo y positivo. A diferencia de lo que solía afirmar parte de la doctrina, para la Corte no es cierto que solamente los derechos económicos, sociales y culturales tengan contenidos prestacionales; los derechos civiles y políticos también requieren de la adopción de medidas, la destinación de recursos y la creación de instituciones para hacerlos efectivos. (...) Adicionalmente, esta Corte ha reconocido que los derechos fundamentales tienen unos contenidos mínimos -negativos y positivos- de cumplimiento inmediato y otros de contenido abierto y sujetos a la configuración legislativa. Sin embargo, la libertad de configuración del legislador de dichos contenidos abiertos e indeterminados no es absoluta; el legislador está sujeto a los principios de no discriminación y progresividad y no regresividad -cuando se trata de contenidos prestacionales-, entre otros (párr. 68.2).

Esta posición de la Corte plantea dos conclusiones: (i) los derechos fundamentales gozan de contenido prestacional, independientemente de su naturaleza y (ii) la vigencia del principio de progresividad en torno a los derechos sociales. Con fundamento en esto, puede decirse que el hecho de la existencia de la progresividad o no regresividad de los derechos sociales se constituye en un límite a la idea de sostenibilidad fiscal. Del mismo modo, debe concluirse que así los derechos individuales o políticos tengan un componente prestacional, no les son predicables el principio de progresividad.

Esta reflexión nos lleva a una conclusión binaria. Por un lado, desde el punto de vista jurídico, los fallos que se produzcan en torno a aspectos que recaigan sobre derechos civiles o políticos deben gozar de aplicación inmediata y sus efectos no se pueden poner en discusión como plantea el hecho de que se interponga el incidente de impacto fiscal. Desde el punto de vista de los derechos económicos, sociales y culturales, si el fallo reconoce estos derechos o atribuye responsabilidad del Estado con efectos económicos, no podrían alterarse los efectos del fallo por cuanto este reconoce un derecho desconocido por el Estado y, como se explicó, se altera el principio de cosa juzgada y de separación de los poderes públicos.

Estas serían las tres razones por las cuales existió una sustitución constitucional que desdibujó la arquitectura constitucional concebida en 1991. 


\section{DE LA INCONVENIENCIA DE CONVERTIR UNA TESIS ECONÓMICA CUESTIONADA EN UNA REGLA CONSTITUCIONAL: AUSENCIA DE INSTITUCIONES INCLUSIVAS Y PACTO SOCIAL}

Las políticas de sostenibilidad fiscal que han venido alterando los panoramas constitucionales en el planeta son producto de la imposición de una ortodoxia económica de los organismos multilaterales de crédito como el Fondo Monetario Internacional y el Banco Mundial que, más de allá de las condiciones propias de cada Estado, están basadas en una idea netamente fiscal, sin parar mientes en el modelo de Estado existente. Estas políticas no soberanas y derivadas de una teoría económica cuestionada se fundan en la idea de libre mercado -en la cual se basó el Consenso de Washington-, que ha derrumbado los pactos sociales estructurados en países en vías de desarrollo a partir de la idea del constituyente primario.

El premio Nobel de Economía Joseph Stiglitz indicó sobre estas medidas de austeridad y la sostenibilidad fiscal lo siguiente:

las políticas comunes que se están discutiendo actualmente son poco más que un pacto de suicidio: un acuerdo para limitar el gasto de acuerdo con los ingresos, incluso durante una recesión, sin un compromiso de los países que gozan de una posición más fuerte para ayudar a los más débiles. Una de las victorias de la Administración Clinton fue la derrota de un intento parecido por parte del Partido Republicano a fin de imponer una enmienda constitucional para garantizar un presupuesto equilibrado (2012, p. 20).

Tan falaz es el argumento económico que respalda estas medidas, que los padres de la proposición, Carmen Reinhart y Kenneth Rogoff (2010), en su artículo Growth in a time of debt indicaron que si se superaba el nivel de endeudamiento del 90\% del PIB, el crecimiento económico desaparecería. Posteriormente, los autores reconocieron un error de cálculo.

Sobre este particular, el premio Nobel de Economía Paul Krugman indicó:

debemos situar el fiasco de Reinhart y Rogoff en el contexto más amplio de la obsesión por la austeridad: el evidentemente intenso deseo de los legisladores, políticos y expertos de todo el mundo occidental de dar la espalda a los parados y, en cambio, usar la crisis económica como excusa para reducir drásticamente los programas sociales. Lo que pone de manifiesto el asunto de Reinhart y Rogoff es la medida en que se nos ha vendido la austeridad con pretextos falsos. Durante tres años, el giro hacia la austeridad se nos ha presentado no como una opción sino como una necesidad. Las investigaciones económicas, insisten los defensores de la austeridad, han demostrado que suceden cosas terribles una vez que la deuda supera el 90\% del PIB. Pero las investigaciones económicas no han demostrado tal cosa; un par de economistas hicieron esa afirmación, mientras que muchos otros no estuvieron de acuerdo. Los responsables políticos abandonaron a los parados y tomaron el camino de la austeridad porque quisieron, no porque tuviesen que hacerlo (2013). 
Esta crítica plantea una idea de la forma como se improvisan las teorías económicas haciéndolas pasar por dogmas, permitiendo que las instituciones políticas y económicas de un Estado sean alteradas.

Tomando como base lo anterior, en este acápite se abordará la ruptura del pacto social que en Colombia se estableció con la Constitución Política de 1991, teniendo en cuenta que los ciudadanos se apropiaron de los mecanismos constitucionales de protección de derechos. A seguida cuenta, se hará una explicación sobre la carencia de instituciones políticas y sociales inclusivas en el país, que impiden una adecuación con la reforma sobre sostenibilidad fiscal.

Para efecto de explicar esto, debe establecerse que la idea de la sostenibilidad fiscal y su consabido desconocimiento de los principios constitucionales, previamente abordados, lleva a que se soslaye el contrato social que había obrado en Colombia, producto de la existencia de mecanismos de protección constitucional. Es necesario tener en cuenta que la sostenibilidad, como se indicó previamente, afectó el principio de cosa juzgada, creando una ruptura del contrato social. Sobre este punto debe recordarse lo indicado por el premio Nobel de Economía Amartya Sen, quien planteó que debe existir un criterio de razonabilidad pública frente al análisis de la justicia (2009, pp. 351 y ss.). Esta idea quiere decir que cualquier decisión que afecte el aparato judicial o sus mecanismos de protección debe gozar de una amplia razonabilidad y deliberación.
En consonancia con esta idea, debe recordarse lo indicado por el profesor norteamericano Charles Epp quien escribió: “Los derechos no son simplemente limosnas que el sistema judicial les da a individuos aislados suplicantes. El respeto de los derechos es el resultado de esfuerzos colectivos y de una estructura de sostén asentado en la sociedad civil" (2013, p. 299).

Desde el ámbito de la sociología, el alemán UIrich Beck (2013, p. 124) explicó que la forma como los Estados europeos pueden atacar la crisis no es a través de políticas puras y simples de austeridad, sino mediante una suerte de contrato social que se componga de dos aristas: la primera, la idea que los ciudadanos europeos se vuelvan parte de las instituciones a través de la democracia material; la segunda, a través del fortalecimiento de esas instituciones. Estas dos ideas son esenciales para establecer un pacto en el cual los ciudadanos se vuelvan parte del debate público, sin perder su individualidad, pero al mismo tiempo engendrando una formación colectiva de razonamiento para construir lo público a través de las múltiples individualidades que componen el Estado. Desde la economía política, Joseph Stiglitz plantea la necesidad de un "nuevo pacto social" en el cual

mantener un tipo de sociedad y un tipo de gobierno que está al servicio de todo un pueblo -que sea coherente con los principios de justicia, de juego limpio y de igualdad de oportunidades- no ocurre así, como así. Alguien tiene que velar por ello. De lo contrario, nuestro gobierno y nuestras instituciones acaban siendo captadas por intereses especiales. Como mínimo necesitamos unos poderes que hagan de 
contrapeso. Pero nuestra sociedad y nuestro sistema de gobierno han acabado estropeándose (2012, p. 347).

Estas ideas permiten con claridad determinar que si en países en desarrollo existe la gran dificultad de afectar el contrato social, en Estados en vía de desarrollo como Colombia es una catástrofe este tipo de medidas de austeridad. Este argumento se fortalece con la idea según la cual los Estados deben tener instituciones políticas y económicas inclusivas y no extractivas. Sobre este particular los profesores Acemoglu y Robinson en su libro Por qué fracasan los países indican que las

instituciones económicas inclusivas que hacen respetar los derechos de propiedad crean igualdad de oportunidades y fomentan la inversión en habilidades y nuevas tecnologías. Estas conducen más al crecimiento económico que las instituciones económicas extractivas, estructuradas para extraer recursos de la mayoría para un grupo reducido y que no protegen los derechos de propiedad ni proporcionan incentivos para la actividad económica. Las instituciones económicas inclusivas, a su vez, respaldan y reciben el apoyo de instituciones políticas inclusivas, es decir, las que reparten el poder político ampliamente de manera pluralista y son capaces de lograr cierto grado de centralización política para establecer la ley y el orden, la base de unos derechos de propiedad seguros y una economía de mercado inclusiva. Asimismo, las instituciones económicas extractivas están relacionadas sinérgicamente con las instituciones políticas extractivas, que concentran el poder en manos de unos pocos, que entonces tendrán incentivos para mantener y desarrollar instituciones económicas ex- tractivas en beneficio propio y utilizar recursos que obtengan para consolidar su control del poder político (2012, p. 501).

Para Banerjee y Duflo, las instituciones como plantearon los teóricos citados, en especial Acemoglu y Robinson, son esenciales, sin embargo es necesario

la comprensión cuidadosa de los motivos y de las restricciones de cada uno (los pobres, los funcionarios, los contribuyentes, los políticos electos, etc.) que pueden conducir a políticas e instituciones mejor diseñadas y menos proclives a sufrir las consecuencias de la corrupción y de la negligencia. Estos cambios serán graduales, pero se sostendrán y crecerán sobre sí mismos. Pueden suponer el comienzo de una revolución silenciosa (2011, p. 326).

Esta idea es respaldada por William Easterly y Jeffrey Sachs, quienes consideran que las instituciones necesitan adaptarse al contexto local (citados por Banerjee y Duflo, 2011, p. 298).

En el caso de Colombia, la falta de instituciones es evidente en la medida en que no se han resuelto, entre otros, los temas de convivencia pacífica, de propiedad de la tierra, de pobreza extrema, de desarrollo, de extracción de recursos no renovables, de ausencia de competencias claras entre el poder central y las entidades territoriales, lo que denota que nuestro proceso de descentralización sea fallido. Sobre esta ausencia de instituciones inclusivas debe recordarse lo indicado por el historiador Marco Palacios (2003), quien plantea la existencia de tres países en Colombia: el país urbano, y dos 
poderes fácticos. El primero es aquel en el cual “la autoridad es respetada, allí es más clara la legitimidad política, son más claras las reglas de la democracia representativa, cada vez son más transparentes los negocios del Estado, etc.". En este se clasifican las grandes ciudades colombianas. Por el lado de los poderes fácticos se destaca el paramilitarismo o los grupos de desmovilizados, muchos de ellos reconvertidos en delincuentes comunes que regresaron al control de las zonas del norte del país. Y, el segundo poder fáctico es la guerrilla que se encuentra en el sur del país y algunos lugares del occidente.

Los dos poderes fácticos se fundan en los intereses de los cultivos ilícitos, de la delincuencia, de las altas tasas de violencia, del contrabando, del secuestro, de la libre e ilimitada negociación y de la burla de la ley. En esos territorios la policía, el poder judicial y el sistema electoral son fachadas.

El vínculo del poder central y los fácticos, según Palacios, se realiza de forma armónica, es decir, en el centro se encuentran los intermediarios "que posibilitan las redes locales, así como los mercados y el Estado brinda cobertura legal y referencia cultural". Añadiría, por mi parte, que el funcionamiento de ese mundo de la facticidad se estructura sobre la base económica central a través de las regalías y participaciones para esas "redes locales" que incluyen actores diversos -guerrilleros, paras, senadores, representantes a la Cámara, gobernadores y alcaldes, entre otros-, quienes realizan los vínculos que plantea Palacios con el poder central (Barbosa, 2008).
Con esta realidad - sin pacto social y sin instituciones políticas inclusivas-, un criterio como el de la sostenibilidad fiscal es una barrera para un Estado que aún carece de lo esencial, y que celebra sus tratados de libre comercio o sus incorporaciones a la OCDE sin tener presente sus carencias, sus defectos y sus debilidades. Esta situación se constata en las recomendaciones de ese organismo para Colombia, en las que le sugiere la descontextualizada idea de establecer salarios mínimos diferenciales por regiones, evento que de por sí demuestra la falta de sintonía con el contexto de nuestro país (OCDE, 2013, pp. 4-5). El economista y miembro del consejo editorial del Cambridge Journal Economics, HaJoon-Chang, nos recuerda en el caso de Corea que cuando este país decidió afiliarse a la OCDE en 1996 “y comportarse como una nación rica cuando en realidad no lo era. Por entonces, su renta per cápita era todavía un tercio de la de la mayoría de países miembros de la ocDE y un cuarto de la de los más ricos. El resultado fue la crisis financiera de 1997" (2009, p. 279).

La reforma constitucional comentada en Colombia dejó una Constitución sin derechos, sin justicia, sin separación de los poderes y con una grave ruptura del pacto social. Sobre las formas como América Latina está abordando el tema constitucional debe traerse a colación lo señalado por el profesor argentino Roberto GargareIla, en cuanto que las reformas constitucionales han sido generosas en la parte de los derechos, pero no se ha tocado la parte orgánica "la sala de máquinas de la Constitución, salvo para reforzar los poderes presidenciales o para facilitar la reelección presidencial" (2012). Añadiría a 
esto, las reformas sobre la sostenibilidad fiscal con intromisión en la idea de realización de derechos y de separación de poderes.

Más allá de desconocer el criterio de sostenibilidad fiscal o la regla fiscal es necesario que existan instituciones que permitan el funcionamiento del Estado colombiano. Esta idea es la base central del constitucionalismo, en la medida en que impide que los principios de separación de los poderes o los pesos o contrapesos tan caros al pensamiento de los enciclopedistas franceses se desdibujen. Bienvenido el ajuste fiscal cuando esté definido el rol del Estado y la existencia de instituciones inclusivas y no extractivas. El Estado de derecho es la respuesta, no el Estado fiscal.

\section{CONSIDERACIONES FINALES}

El modelo deliberativo derivado de nuestra Carta política, y que desde la filosofía política y la economía del desarrollo ha sido planteado por teóricos como Amartya Sen quien opina que debe existir un criterio de razonabilidad pública frente al análisis de la justicia, o la misma idea de Stiglitz, Habermas y Beck en torno a los nuevos contratos sociales, propone un serio desafío frente a dispositivos como el de la sostenibilidad fiscal que no solo alteran el escenario democrático-deliberativo de nuestra Carta Política, sino que producen una ruptura en el pacto social instaurado por el proceso constituyente en Colombia. El hecho mismo de alterar el principio de separación de poderes, de limitar la efectividad de los derechos y el de cosa juzgada, olvida la definición que del derecho dio Hegel como el reino de la libertad realizada. De todo esto nos queda una Constitución con muchos principios sin realizar, y con una lógica de funcionamiento que empieza a denotar una inidentidad con un verdadero pacto social.

Recordemos lo que indicaron los profesores norteamericanos Holmes y Sunstein en el sentido en que "sin Estado no hay derechos" (2011, p. 18), pero también pongamos de presente que sin derechos realizables no hay Estado, por cuanto los deberes recíprocos de protección y obediencia desaparecerían y se regresaría a un mundo mucho más hobbesiano, individualista y menos fundado en los principios de comunidad emanados de maestros como Aristóteles, Marsilio de Padua y los contractualistas del siglo XVIII y XIX.

\section{Referencias}

Abramovich, V. y Courtis, C. (2004). Los derechos sociales como derechos exigibles. Madrid: Editorial Trotta.

Acemoglu, D. y Robinson, J. (2012). Por qué fracasan los países. Barcelona: Editorial Deusto.

Banerjee, A. y Duflo, E. (2011). Repensar la pobreza. Un giro radical en la lucha contra la desigualdad global. Bogotá: Editorial Taurus.

Barbosa Delgado, F. (5 de diciembre de 2008). Margen cultural. Recuperado de: 
http://margencultural.blogspot.com/ search?q=marco + palacios

Barbosa Delgado, F. (Julio-Diciembre de 2011). La democracia: un concepto base dentro de los sistemas de protección de derechos humanos. Revista Derecho del Estado (27), 177-191.

Barbosa Delgado, F. (2012). El margen nacional de apreciación y sus límites en la libertad de expresión. Bogotá: Universidad Externado de Colombia.

Beck, U. (2013). À l'Europe Allemande, Vers un printemps européen? Paris: Éditions Autrement.

Casenove, E. (1994). Ordre juridique et démocratie dans la jurisprudence de la Cour Européenne des droits de l'homme. [Tesis sin editar].

Cataño, G. (2013). La introducción del pensamiento moderno en Colombia. El caso de Luis E. Nieto Arteta. Bogotá: Universidad Externado de Colombia.

Corte Constitucional. Sentencia C-141 de 2010.

Corte Constitucional. Sentencia C-288 del 18 de abril de 2012.

Corte Interamericana de Derechos Humanos. Caso Furlan y familiares c. Argentina. Sentencia del 31 de agosto de 2012. Obtenido de: http://www.corteidh.or.cr/docs/casos/ articulos/seriec_246_esp.pdf
Chang, H.-J. (2009). ¿Qué fue del buen samaritano? Naciones ricas, políticas pobres. Buenos Aires: Universidad Nacional de Quilmes y AEDA.

De Botton, A. (2012). Religión para ateos. Barcelona: RBA Libros.

Epp Charles, R. (2013). La revolución de los derechos. Buenos Aires: siglo XXI Editores.

Fabre-Alibert, V. (1998). La notion de société démocratique dans la jurisprudence de la Cour européenne des droits de l'homme. Revue Trimestrielle des droits de l'homme (35), 465-496.

García Amado, J. A. (1997). La Filosofía del derecho de Habermas y Luhmann. Bogotá: Universidad Externado de Colombia.

Gargarella, R. (3 de mayo de 2012). Ir a la sala de máquinas del poder. Obtenido de Clarin. com: http://www.clarin.com/opinion/Ir-salamaquinas-poder_0_693530727.html

Gicquel, J. y Gicquel, J. E. (2008). Droit constitutionnel et institutions politiques (22 édition). Paris: Donnant droit public.

Gross Espiell, H. (1998). Commission et Cour Interaméricaines. En Mélanges en hommage á Louis Edmond Pettiti. Bruxelles: Bruyland.

Holmes, S. y Sunstein, C. (2011). El costo de los derechos. Buenos Aires: Siglo XXI Editores. 
Kelsen, H. (1988). La démocratie, sa nature, sa valeur. Paris: Económica.

Kelsen, H. (1999). Théorie Pure du droit. Bruxelles: Bruylant.

Krugman, P. (21 de abril de 2013). La depresión de Excel. Obtenido de El País: http://economia.elpais.com/economia/2013/04/19/actualidad/1366398440_370422.html

Liechti, V. (2010). Mesurer l'effectivité del droit à l'education. En Le droit à l'education quelle universalité? Paris: Éditions des archives contemporaines.

Loewenstein, K. (1964). Teoría de la Constitución. Barcelona: Ariel.

Melvevik, B. (2006). Rawls o Habermas. Un debate de filosofía del derecho. Bogotá: Universidad Externado de Colombia.

Naciones Unidas. Convención Americana sobre Derechos Humanos -CADH. Obtenido de http://www.cidh.org/Basicos/Basicos2.htm.

Naciones Unidas. Convenio para la Protección de los Derechos Humanos y de las Libertades Individuales -CEDH.

Organización para la Cooperación y el Desarrollo Económicos. (Enero de 2013). Estudios económicos de la OCDE. Colombia. Evaluación económica. Visión general. Obtenido de siicex.gob: en http://www.siicex.gob.pe/siicex/documentosportal/alertas/documento/ doc/192121742radF9D1F.pdf
Pactet, P. y Mélin-Soucramanien, F. (2008). Droit Constitutionnel. (27 édition). Paris: Dalloz Librairie.

Palacios, M. (2003). Entre la legitimidad y la violencia: 1875-1994. Bogotá: Editorial Norma.

Pessoa, F. (2011). Libro do Desassossego. Sao Paulo: Companhia de Bolso.

Programa de las Naciones Unidas para el Desarrollo. (2004). La democracia en América Latina. Hacia una democracia de ciudadanas y ciudadanos. Buenos Aires: Alfagura.

Reinhart, C. y Rogoff, K. (Enero de 2010). Growth in a time of debt. Obtenido de The National Bureau of Economic Research: http://www. nber.org/papers/w15639

Restrepo Piedrahita, C. (Comp.). (2000). Constituciones políticas nacionales de Colombia. Bogotá: Universidad Externado de Colombia.

Rosanvallon, P. (2008). La légitimé démocratique: impartialité, réflexivité, proximité. Paris: Seuil.

Sen, A. (2009). La idea de justicia. Bogotá: Taurus.

Skidelsky, R. (2013). John Maynard Keynes. Barcelona: RDA libros.

Stiglitz, J. (2012). El precio de la desigualdad. Bogotá: Editorial Taurus. 
Tribunal Europeo de Derechos Humanos -TEDH. Van Boven, T. (1990). Democratie, droits de Caso Partido Comunista Unificado de Tur- l'homme et solidarité. Démocratie et droits quía c. Turquía, 30 de enero 1998. de l'homme. Strasbourg: N. P. Engel.

Troper, M. (2004). Le pouvoir judiciare et la dé- Villar Borda, L. (2007). Estado de derecho y Esmocratie. En G. Cohen-Jonathan, Libertés, tado social de derecho. Revista de Derecho justice, tolérance: mélanges en hommage del Estado (20). Bogotá: Universidad Exterau doyen Gérard Cohen-Jonathan (Vol. II). nado de Colombia. Bruxelles: Bruylant.

Trujillo, A. y Trujillo, I. (2003). La polémique relative á la juridicité des droits sociaux. En Fondations et naissances des Droits de l'homme. L'Odysee des Droits de I'homme. Paris: L. Harmattan.

Wachmann, P. (Juillet-Août 1998). Participation, communication, pluralisme. En E. Picard, Les droits fondamentaux. Une nouvelle catégorie juridique? Paris: Groupe Moniteur. 